\title{
Tecnologia Assistiva e Educação Especial Inclusiva: o Estado da Arte nas Pós-Graduações do Brasil
}

\author{
Assistive Technology and Inclusive Special Education: the State of Art in \\ Brazil's graduates
}

\section{Tecnología de Asistencia y Educación Especial Inclusiva: el Estado del Arte en los Graduados de Brasil}

\author{
Samuel Pires Melo \\ Professor doutor da Universidade Federal do Delta do Parnaíba, Parnaíba, PI, Brasil \\ E-mail: sampires@hotmail.com ORCID: https://orcid.org/0000-0003-0655-2917

\section{Leonam Costa Oliveira} \\ Professor doutor da Universidade Federal do Delta do Parnaíba, Parnaíba, PI, Brasil \\ E-mail: leonam_costa@yahoo.com.br ORCID: https://orcid.org/0000-0003-4559-7202
}

Recebido em 24 de fevereiro de 2021

Aprovado em 17 de maio de 2021

Publicado em 21 de junho de 2021

\section{RESUMO}

O estudo busca oferecer, pela perspectiva das Pós-Graduações do Brasil, uma discussão das teses e dissertações defendidas entre período de 2015 e 2019 sobre os usos da Tecnologia Assistiva na Educação Especial Inclusiva. Foi realizado um estudo do tipo estado da arte, pelo levantamento dos trabalhos localizados no banco de teses e dissertações da Coordenação de Aperfeiçoamento de Pessoal de Nível Superior. Estes foram investigados por meio da teoria dos grafos e a classificação hierárquica descendente, utilizando os softwares IRAMUTEQ e o EXCEL. Os resultados apontam para a existência de 42 trabalhos, neles seus autores pesquisam na área de Educação Especial desde sua formação no Ensino Superior, com interseção à Tecnologia Assistiva mais recentemente no processo de ensino-aprendizagem, principalmente com inquietações sobre a maneira como os recursos de Tecnologia Assistiva podem auxiliar na Educação Especial Inclusiva. Observou-se nessa linha de análise que há um envolvimento dos alunos nas atividades, embora à participação ativa em seu processo de aprendizagem dependesse de formação docente para atuar com esses recursos, produzindo um dos maiores desafios. Tal investigação, portanto, relaciona os resultados das pesquisas com a trajetória acadêmica dos autores, possibilitando assim, uma visão geral do que vem sendo produzido sobre essas temáticas e uma ordenação que permite perceber as transformações desse campo.

Palavras-chave: Educação Especial Inclusiva; Tecnologia Assistiva; Estado da arte.

\section{ABSTRACT}

The study seeks to offer, from the perspective of Postgraduate Studies in Brazil, a discussion of the theses and dissertations defended between 2015 and 2019 on the uses of Assistive Technology in Special Inclusive Education. A state-of-the-art study was carried out, by 
http://dx.doi.org/10.5902/1984686X64421

surveying the works located in the bank of theses and dissertations of the Coordination for the Improvement of Higher Education Personnel. These were investigated through graph theory and descending hierarchical classification, using the software IRAMUTEQ and EXCEL. The results point to the existence of 42 studies, where their authors have been researching in the area of Special Education since their formation in Higher Education, with the intersection of Assistive Technology more recently in the teaching-learning process, mainly with concerns about the way the resources of Assistive Technology can assist of Special Inclusive Education. It was observed in this line of analysis that there is involvement of students in activities, although active participation in their learning process depended on teacher training to work with these resources, producing one of the greatest challenges. Such an investigation, therefore, links the results of the research with the academic trajectory of the authors, thus enabling an overview of what has been produced on these themes and an ordering that allows us to perceive the transformations in this field.

Keywords: Inclusive Special Education; Assistive Technology; state of art.

\section{RESUMEN}

El estudio busca ofrecer, desde la perspectiva de los estudios de posgrado en Brasil, una discusión de las tesis y disertaciones defendidas entre 2015 y 2019 sobre los usos de la Tecnología Asistiva en la Educación Especial Inclusiva. Se realizó un estudio de vanguardia, mediante el relevamiento de los trabajos ubicados en el banco de tesis y disertaciones de la Coordinación para la Perfeccionamiento del Personal de Educación Superior. Estos fueron investigados a través de la teoría de grafos y la clasificación jerárquica descendente, utilizando el software IRAMUTEQ y EXCEL. Los resultados apuntan a la existencia de 42 trabajos, donde sus autores han estado investigando en el área de Educación Especial desde su formación en Educación Superior, con la intersección de la Tecnología Asistiva más recientemente en el proceso de enseñanza-aprendizaje, principalmente con inquietudes sobre la forma en que los recursos de la tecnología de asistencia pueden ayudar de la educación especial inclusiva. En esta línea de análisis se observó que existe una implicación de los estudiantes en las actividades, aunque la participación activa en su proceso de aprendizaje dependía de la formación del profesorado para trabajar con estos recursos, produciendo uno de los mayores retos. Tal investigación, por tanto, vincula los resultados de la investigación con la trayectoria académica de los autores, permitiendo así un panorama de lo que se ha producido sobre estos temas y un ordenamiento que permita percibir las transformaciones en este campo.

Palabras clave: Educación especial inclusiva; Tecnología de asistencia; Estado del arte.

\section{Introdução}

É importante dizer que nas últimas décadas têm-se referenciado no Brasil a Educação Especial, muito embora se tenham equivocadamente colocada como sinônimo de educação segregada. A Educação Especial é uma modalidade de ensino que deve ocorrer preferencialmente na perspectiva inclusiva, mas também como uma área de 
http://dx.doi.org/10.5902/1984686X64421

produção do conhecimento que produz conhecimento sobre o desenvolvimento de pessoas com deficiência e as diferentes implicações que isso pode ter na formação de professores, no uso da tecnologia, entre outros.

Entre esses equívocos, em diversos momentos históricos, pensou-se que os educandos com deficiência deveriam estar matriculados em instituições especializadas, recebendo educação especializada, substituindo o ensino comum. Estes alunos também poderiam ser encaminhados para classes especiais, em que receberiam o atendimento educacional separadamente dos demais alunos. No entanto, cada vez mais, crianças com deficiência estão frequentando escolas comuns, o que demonstra uma mudança de visão da sociedade brasileira e das famílias em relação à educação de crianças com deficiência. Mais do que isso, "o movimento mundial pela inclusão é uma ação política, cultural, social e pedagógica desencadeada em defesa do direito de todos os alunos estarem juntos, aprendendo e participando, sem nenhum tipo de discriminação" (BRASIL, 2008, p. 138).

Entre as demandas dos alunos com deficiência observadas historicamente, verificase que em 2008 foi implementada a Política Nacional de Educação Especial na perspectiva da Educação Inclusiva (PNEEI). Essa medida ampliou o acesso destes alunos a escolas regulares, bem como o Atendimento Educacional Especializado (AEE), que tem como uma de suas estratégias as Salas de Recursos Multifuncionais (SRM), com equipamentos e recursos facilitadores do aprendizado a serem utilizados no contraturno do ensino regular (BRASIL, 2008).

Há de salientar, por outro lado, que temos desde a Constituição Federal do Brasil de 1988 uma proposta sobre a escolarização de discentes com alguma deficiência ocorrer preferencialmente no sistema comum de ensino. O que de certa forma se consigna é a educação inclusiva ser mais recente nas políticas nacionais a partir de 2001, e sob a mediação da Tecnologia Assistiva (TA) com PNEEI, em 2008. Por outro lado, vale dizer que o direito de acessibilidade aos recursos e serviços da Tecnologia Assistiva foi decretado no Art.61 do decreto 5296 de dezembro de 2004, em que consideram-se "as ajudas técnicas, os produtos, instrumentos, equipamentos ou tecnologia adaptados ou especialmente projetados para melhorar a funcionalidade da pessoa portadora de deficiência ou com mobilidade reduzida" (BRASIL, 2004, p.03).

Ao destacar a relação da Tecnologia Assistiva com a Educação Especial Inclusiva (EEI), observa-se que sua importância se relaciona, dentre outras circunstâncias, com a utilização de recursos facilitadores no aprendizado de pessoas com alguma deficiência. 
http://dx.doi.org/10.5902/1984686X64421

No caso da PNEEI, ela aponta para a necessidade de recursos tecnológicos de apoio e profissionais preparados para a realização do atendimento educacional especializado. A Tecnologia Assistiva se apresenta, assim, como viabilizadora de uma participação social e facilitadora junto ao educando com deficiência, apoiando seu desenvolvimento (VARELA; OLIVER, 2013), com promoção de maior independência e autonomia no dia a dia deste educando. Vale destacar, segundo Pelosi \& Nunes (2009), que dentro deste universo, "há alunos que necessitam de mediação todo o tempo em que estão na sala de aula", como, por exemplo, "os alunos com déficits motores mais graves muitas vezes não são capazes de falar para responder às solicitações do professor, [...] contudo, estes mesmos alunos podem aprender e se expressar se lhe for oferecida maior acessibilidade" (p.141).

Nesse sentido, compreender a TA como um instrumento catalisador e estimulador na construção de novas perspectivas de atuação inclusiva da Educação Especial é verificar o lugar de mudanças necessárias para o aprendizado e desenvolvimento dos que apresentam algum tipo de deficiência, pois disponibiliza recursos para o "empoderamento" dessas pessoas, permitindo que possam interagir, relacionar-se e competir em seu meio (GALVÃO, 2009). No entanto, Manzini (2013) aponta outros elementos necessários a esse processo, como, por exemplo, a atualização profissional sob os alicerces básicos dos processos de ensinar e aprender, porque "sem os processos de mediação adequados para ensino-aprendizagem, os recursos e os equipamentos de tecnologia assistiva, por si só, não trarão contribuição" (p. 21).

$\mathrm{Na}$ verdade, a Tecnologia Assistiva pode reorganizar certas possibilidades da Educação Especial, ganhando potência quando aliadas, neste âmbito, à formação dos profissionais da educação para outras perspectivas de atuação inclusiva. Para Rocha (2013, p. 30), a TA "quando utilizada por serviços capacitados pode garantir o acesso ao conteúdo escolar e o desenvolvimento de habilidades fundamentais para todo o processo de ensino e aprendizagem", embora "os estudos também identificam que o seu uso ainda é restrito e está longe de ser ideal" (p. 1).

Em uma revisão sistemática realizada por Souza \& Mendes (2017) sobre pesquisas colaborativas em Educação Especial na perspectiva da inclusão escolar no Brasil, observou-se que os estudos que evidenciam ações interventivas apresentaram como discussão primeira as categorias que levam em consideração tanto os elementos internos e externos ao espaço escolar: ensino-aprendizagem; atuação docente; formação de 
http://dx.doi.org/10.5902/1984686X64421

professores; e formação de outros profissionais da escola e da saúde que atuam em parceria com a escola.

Em relação ao processo de ensino-aprendizagem [...] a) O coensino é um modelo de serviço favorável à inclusão de alunos PAEE na classe comum [...]; b) A compreensão pelo professor de seu papel como mediador pode colaborar [...]; c) O ensino do PAEE deve ser diversificado [...] e d) As atividades [...] para atender aos alunos PAEE, devem ser relacionadas aos objetivos de ensino propostos para a classe como um todo [...] No que se refere à atuação docente [...] a) As ações colaborativas podem contribuir para a superação de problemas vividos pelos professores da SEM; b) É necessário a existência de espaços físicos adequados para o desenvolvimento de práticas pedagógicas eficientes, além de uma rede de apoio colaborativa; $\mathrm{c}$ ) Pode-se questionar a funcionalidade do trabalho desenvolvido nas SRM junto aos alunos PAEE [...]; d) Há necessidade de elaboração de planejamentos de ensino individuais (PEI) [...] de forma articulada e colaborativa entre todos os profissionais [...] e e) [...] que sejam criados recursos adaptados [...] No que tange a formação de professores [...] a) [...] deve ocorrer de acordo com suas demandas de atuação [...]; b) A formação do professor para o uso de recursos de informática e de tecnologias assistivas é necessária para que seja feito o uso adequado desses recursos; e c) $O$ ensino colaborativo ou coensino contribui para a formação continuada dos professores da educação especial e da classe comum [...] $\mathrm{Na}$ categoria formação dos demais profissionais escolares e da saúde [...] a) O trabalho colaborativo é importante para a formação de todos os profissionais da educação que atuam com a inclusão do PAEE; b) Ações colaborativas transdisciplinares entre diferentes profissionais de distintas áreas de atuação e disciplinas contribuem para a formação profissional e para a produção de materiais; c) $O$ trabalho colaborativo do Terapeuta Ocupacional no contexto escolar e os profissionais da escola [...]; d) O papel do supervisor educacional é fundamental [...]; e) É importante o desenvolvimento da gestão compartilhada na construção de escolas inclusivas; e f) A família deve ser envolvida nas discussões acerca da inclusão escolar dos alunos PAEE. (SOUZA; MENDES, 2017, pp. 287-8)

Ao destacar os elementos internos e externos ao ambiente escolar como aspectos necessários à produção inclusiva, constata-se o avanço de estudos qualificados na área da Educação Especial. Embora, estes, ao salientarem a formação de docentes para trabalharem com recursos de informática e de Tecnologia Assistiva para o uso adequado deles, careçam de um mapeamento mais relacional destes trabalhos. Por isso, questionase quais discussões estão sendo produzidas pelos pesquisadores das Pós-graduações sobre os usos da Tecnologia Assistiva na Educação Especial Inclusiva.

Tem-se a hipótese de que há uma discussão sendo aperfeiçoada nas teses e dissertações sobre Educação Especial Inclusiva, que quando aliada com a Tecnologia Assistiva, pode ocupar novos cenários discursivos, principalmente pela interação significada dos profissionais inseridos no ambiente escolar. No entanto, essas pesquisas evidenciam uma necessidade de formação inicial e continuada para uso e produção 
http://dx.doi.org/10.5902/1984686X64421

dessas TA, principalmente em decorrência do (não)lugar que essas "ocupam" na cultura escolar brasileira.

O recorte temporal entre 2015 e 2019 foi definido considerando que essa produção mais recente não foi sistematizada por outros pesquisadores e a agenda de políticas propostas em âmbito mundial para esse grupo social. Nestas, destacam-se o Marco de Ação da Educação 2030 e os usos da Tecnologia Assistiva na Educação Especial Inclusiva. Este Marco visa mobilizar os países e parceiros em torno dos objetivos de desenvolvimento sustentável para a educação, além de propor formas de implementar, coordenar, financiar e monitorar a Educação 2030 para garantir oportunidades de educação de qualidade inclusiva e equitativa, assim como de aprendizagem ao longo da vida para todos (UNESCO, 2015).

Espera-se que os resumos das teses e dissertações obtidos nestas investigações sobre TA e EEI, possam contribuir para o avanço das pesquisas voltadas para Educação Especial, principalmente quando se busca a interação com as trajetórias dos pesquisadores. Diante disso, definiu-se como objetivo deste trabalho descrever e analisar a relação entre a Educação Especial Inclusiva pela perspectiva dos usos de Tecnologia Assistiva, no período entre 2015 e 2019, tomando como fonte as teses e dissertações nacionais disponível no banco de dados da Coordenação de Aperfeiçoamento de Pessoal de Nível Superior (CAPES).

\section{Metodologia}

Este estudo do tipo Estado da Arte não se restringe a identificar os produtores e sua produção, mas relacioná-las, analisá-las, categorizá-las e revelar seus múltiplos enfoques e perspectivas. Segundo Soares e Maciel (2000, p. 04), em um estado da arte é necessário considerar categorias que identifiquem, em cada texto e no conjunto deles, as facetas sobre as quais o fenômeno vem sendo analisado. Pensando nisso, buscou-se situar aspectos das trajetórias formativas e de produção científica dos autores e como estes possibilitam pensar na análise da relação entre a Educação Especial Inclusiva pela perspectiva dos usos de Tecnologia Assistiva.

Como primeira estratégia para obtenção dos dados que pudessem traçar aspectos das trajetórias formativas e de produção científica dos autores, utilizou-se da plataforma lattes (http://lattes.cnpq.br/). Nela, obteve-se informações sobre a formação inicial dos sujeitos das teses e dissertações, o ano em que esses autores pesquisados iniciaram 
http://dx.doi.org/10.5902/1984686X64421

suas publicações sobre o tema, quantidade de trabalhos publicados sobre o tema, eventos que participaram envolvendo a temática, atividades de Extensão realizadas envolvendo o tema e atividades de Ensino realizadas envolvendo a temática. As demais informações foram coletadas nas teses e dissertações.

As teses e dissertações foram coletadas a partir dos resumos de dissertações e teses indexadas no banco de dados da CAPES, encontrado no endereço: http://bdtd.ibict.br/. Essa busca foi realizada por meio de uma associação em pares entre os seguintes descritores: Tecnologia Assistiva; Educação Especial; Educação Especial Inclusiva. Foram incluídas as teses e dissertações que apresentaram os descritores em seus títulos, resumos ou palavras-chave, que estavam circunscritas ao campo da TA e da EEI; e que tenham sido defendidas entre os anos de 2015 e 2019 . Foram excluídos os trabalhos realizados fora do contexto de escolarização; os que não tiveram como alvo os usos da Tecnologia Assistiva na Educação Especial; aqueles que não abordavam o tema Educação Especial Inclusiva; e os estudos teóricos.

Inicialmente, foram encontrados 76 trabalhos, dos quais foram selecionados, em uma primeira triagem, 61 pesquisas, sendo 42 dissertações e 19 teses. Os demais foram desconsiderados por se enquadrarem nos critérios de exclusão ou por serem trabalhos repetidos. Após leitura analítica dos resumos dos trabalhos selecionados foi realizada uma segunda triagem, que resultou na escolha de 34 dissertações e oito teses. Foram retirados 14 trabalhos (dez dissertações e quatro teses) por se tratarem de tipos de pesquisa que não se adequaram a este estudo e cinco (três dissertações e duas teses) por serem trabalhos repetidos. Os resumos das 42 pesquisas escolhidas foram analisados com base em um protocolo contendo categorias sob duas perspectivas: 1) trajetórias formativas e de atuação do autor na temática estudada; 2) características da dissertação/ tese (o título; tipo de pesquisa; objetivos; participantes; processo conceitual dos temas Educação Especial Inclusiva e Tecnologia Assistiva; procedimento de coleta/análise; resultados/ conclusões). Estas informações foram organizadas em um quadro geral a fim de auxiliar no processo de sistematização e análise dos dados pelos softwares Microsoft Office Excel e IRAMUTEQ.

Para tabulação e análise das trajetórias dos autores, utilizou-se do software Microsoft Excel, a partir de uma estatística descritiva de distribuição de frequência. No que diz respeito ao IRAMUTEQ, trata-se de um software gratuito e desenvolvido sob a lógica do open source, licenciado por GNU GPL (v2). Ele ancora-se no ambiente 
estatístico do software $R$ e na linguagem python (www.python.org) (CAMARGO; JUSTO, 2013). Ele viabiliza diferentes tipos de análise de dados textuais, desde aquelas bem simples, como a lexicografia básica [Nuvem de palavras e análise de similitude] até análises multivariadas [Classificação Hierárquica Descendente] (CAMARGO; JUSTO, 2013).

\begin{abstract}
A análise de similitude ou de semelhanças apoia-se na teoria dos grafos, pois um grafo constitui o modelo matemático ideal para o estudo das relações entre objetos discretos de qualquer tipo e possibilita identificar as coocorrências entre as palavras e o seu resultado, traz indicações da conexidade entre as palavras, auxiliando na identificação da estrutura de um corpus textual, distinguindo também as partes comuns e as especificidades em função das variáveis ilustrativas (descritivas) identificadas na análise [...] A nuvem de palavras agrupa e organiza as palavras graficamente em função da sua frequência. É uma análise lexical mais simples, porém graficamente bastante interessante, na medida em que possibilita a rápida identificação das palavras-chave de um corpus. (MENDES et al.; 2016, p. 347)
\end{abstract}

Formulou-se, a partir deste programa, um corpus de textos "características das dissertações/ teses", que foi dividido nos subcorpus "título; tipo de pesquisa; objetivos; participantes; processo conceitual dos temas Educação Inclusiva e Tecnologia Assistiva; procedimento de coleta/análise; resultados/ conclusões". Sob estes subcorpus, procurou tratar pelo IRAMUTEQ com a análise de similitude, o método da nuvem de palavras e a Classificação Hierárquica Descendente (CHD).

\title{
Resultados e discussão
}

\section{Enlaçando a Tecnologia Assistiva pelas trajetórias de pesquisadores na Educação Especial Inclusiva}

Não é novidade o estudo sobre a produção do conhecimento que envolva a Educação Especial. Para se ter uma ideia, Ferreira (1991) buscou analisar os resumos das dissertações e teses defendidas nos Programas de Pós-Graduação em Educação no Brasil contidos nos catálogos da ANPEd no período entre 1981 e 1988, assim como os trabalhos de Nunes et al. (2004), que desenvolveram seus estudos com o objetivo de mapear e analisar a produção discente dos Programas de Pós-Graduação Stricto Sensu em Educação e Psicologia, voltada para o indivíduo com necessidades educacionais especiais.

Essas análises trouxeram uma dimensão importante para a EE. No entanto, há de se inquietar sobre a discussão temática bem como os caminhos percorridos pelos 
http://dx.doi.org/10.5902/1984686X64421

pesquisadores envolvendo esses estudos, principalmente no sentido de situar suas trajetórias com a temática estudada. Pensando nisso, observou-se neste estudo que, embora o recorte temporal seja de 2015 a 2019, e a maior frequência das teses e dissertações tenha se dado em 2018 (28,6\%), muitos desses pesquisadores começaram a trabalhar com o tema da EE, sem necessariamente estar relacionada à $T A^{1}$, na década de 1990 (9,5\%) e 2000 (45,3\%), principalmente na graduação, sejam como expectadores em eventos científicos ou apresentando artigos nesses eventos (Ver tabela 1).

Especificamente, pode-se destacar que vários $(26,2 \%)$ pesquisadores têm pelo menos um trabalho publicado envolvendo o tema e quase a metade (42,8\%) tem entre 14 e 89 publicações, com uma média de 9 estudos, sejam artigos em periódicos, livros, capítulos de livros, trabalhos técnicos ou em Anais de eventos. Sobre esta última forma de divulgação é importante dizer que quase a metade $(37,9 \%)$ desses estudiosos participou de 1 a 6 reuniões científicas (Ver tabela 1).

Por outro lado, vale dizer que o nível de produção e divulgação das pesquisas desses pesquisadores não segue o mesmo ritmo no ensino e extensão. Para se ter uma ideia, um pouco mais da metade (54,8\%) deles não realizou atividades que envolvesse ensino, e quase a metade (47,6\%) deles não desenvolveu extensão universitária. (Ver tabela 1). Isso pode ter relação com a falta de institucionalização da Educação Especial Inclusiva nas Instituições de Ensino Superior. Segundo Buenos (2002, p. 27),

\footnotetext{
Não se pode deixar de apontar o reduzido número de cursos voltados às deficiências físicas e sensoriais (8 para todo o País), o que dá a dimensão da precariedade de atendimento nessas áreas. Se o número de cursos de professores de deficientes auditivos era reduzidíssimo, o de professores de deficiência visual e física foram ínfimos, esta última área contando com um único curso em todo o País.
}

Há de se salientar que, apesar desse déficit no número de cursos voltados para educação especial inclusiva, as teses e dissertações aqui analisadas apontam para uma atenção de diversos Programas de Pós-Graduação ao tema, seja por meio de pesquisadores $(28,6 \%)$ ou pesquisadoras (71,4\%). Especificamente, destacam-se frequências variadas de participação dos cursos nas áreas de Ciências Humanas e Sociais Aplicadas (66,9\%), Ciências Exatas, da Terra e Engenharias (18,8\%), e Ciências Biológicas (14,3\%). É possível destacar ainda um número reduzido (19\%) de teses defendidas. Tendo a maior participação dos trabalhos sido concluídos nos anos de 2015 $(26,2 \%)$ e 2018 (28,6\%), nas regiões Nordeste (33,3\%) e Sudeste (33,3\%) (Ver tabela 1). 
A variedade de cursos de Pós-Graduação incita pensar que a interdisciplinaridade na Educação Inclusiva, tratada nessas Teses e Dissertações, toma dimensões variadas. A própria formação dos autores desses trabalhos também é outro indicador. As graduações mais representativas foram Pedagogia (23,8\%), Computação (14,3\%), Educação Física $(11,9 \%)$, Letras $(11,9 \%)$ e dentre outros $(38,1 \%)$ (Ver tabela 1). Além dos diversos cursos que constroem os estudos sobre El e TA, foi possível observar na análise dos currículos lattes dos autores a formação continuada em áreas distintas de sua formação inicial, isso possibilita pensar uma interdisciplinaridade, principalmente porque o "que caracteriza a atitude interdisciplinar é a ousadia da busca, da pesquisa: é a transformação da insegurança num exercício do pensar, no construir" (FAZENDA, 1999, p. 18).

Tabela 1 - Trajetória dos autores das teses e dissertações

(continua)

\begin{tabular}{l|l}
\hline VARIÁVEIS & $\mathbf{n}(\%)$ \\
\hline Gênero & $12(28,6)$ \\
Masculino & $30(71,4)$ \\
Feminino & $42(100)$ \\
Total & \\
\hline Graduação dos autores & $10(23,8)$ \\
Pedagogia & $6(14,3)$ \\
Computação & $5(11,9)$ \\
Letras & $5(11,9)$ \\
Educação Física & $16(38,1)$ \\
Outras & $42(100)$ \\
Total & \\
\hline Ano de defesa das Teses e Dissertações & $11(26,2)$ \\
2015 & $6(14,3)$ \\
2016 & $8(19,0)$ \\
2017 & $12(28,6)$ \\
2018 & $5(11,9)$ \\
2019 & $42(100)$ \\
Total & \\
\hline Áreas dos Programas de Pós-Graduação & $28(66,9)$ \\
Ciências Humanas e Sociais Aplicadas & $8(18,8)$ \\
Ciências Exatas, da Terra e Engenharias & $6(14,3)$ \\
Ciências Biológicas & $42(100)$ \\
Total & \\
\hline Região dos Programas de Pós-Graduação & $4(9,5)$ \\
Centro-Oeste & $14(33,3)$ \\
Nordeste & $2(4,8)$ \\
Norte & $14(33,3)$ \\
Sudeste & $8(19)$ \\
Sul & $42(100)$ \\
Total & $34(81,0)$ \\
\hline Nível dos Programas de Pós-Graduação & $8(19,0)$ \\
Mestrado & $42(100)$ \\
Doutorado & \\
Total & \\
\hline
\end{tabular}


http://dx.doi.org/10.5902/1984686X64421

Tabela 1 - Trajetória dos autores das teses e dissertações

(conclusão)

\begin{tabular}{l|l}
\hline VARIÁVEIS & $\mathbf{n}(\%)$ \\
\hline Ano com início de publicações sobre o tema & $\mathbf{4}(\mathbf{9 , 5})$ \\
$1991-2000$ & $\mathbf{1 9}(\mathbf{4 5 , 3 )}$ \\
$2001-2010$ & $\mathbf{1 9}(\mathbf{4 5 , 3 )}$ \\
$2011-2017$ & $\mathbf{4 2}(\mathbf{1 0 0 )}$ \\
Total & $1(2,4)$ \\
\hline Quantidade de trabalhos publicados sobre o tema & $10(23,8)$ \\
11 & $13(31,0)$ \\
$2-5$ & $18(42,8)$ \\
$6-10$ & $42(100)$ \\
$14-89$ & \\
Total & $9(21,4)$ \\
\hline Eventos que participou envolvendo o tema & $16(37,9)$ \\
0 & $9(21,4)$ \\
$1-6$ & $8(19,3)$ \\
$7-14$ & $42(100)$ \\
$15-60$ & \\
Total & $20(47,6)$ \\
\hline Atividade de Extensão realizada envolvendo o tema & $15(35,8)$ \\
0 & $7(16,6)$ \\
$1-2$ & $42(100)$ \\
$3-7$ & \\
Total & $23(54,8)$ \\
\hline Atividade de Ensino realizada envolvendo o tema & $11(26,1)$ \\
0 & $8(19,1)$ \\
$1-2$ & $42(100)$ \\
$3-20$ & $42(100)$ \\
Total & \\
\hline TOTAL & \\
\hline
\end{tabular}

Fonte: Dados da pesquisa (2020).

\section{O que dizem as Teses e dissertações do Brasil sobre a relação entre Educação} Especial Inclusiva e Tecnologia Assistiva

Verificou-se nas trajetórias dos autores dessas teses e dissertações uma relação de proximidade com a Educação Especial Inclusiva, independente das formações iniciais, posto que os pesquisadores eram de diversas áreas, desde a graduação aos programas de Pós-graduação de mestrado e doutorado. Vale salientar que essas trajetórias não estiveram completamente relacionadas com a Tecnologia Assistiva, principalmente nas formações iniciais. Pensando então em esclarecer os pontos de intercessões, iniciou-se a discussão analisando a relação entre EEI e TA sob o título desses trabalhos das teses e dissertações pela árvore de similitude, representada na figura 1. 
http://dx.doi.org/10.5902/1984686X64421

Figura 1 - Árvore de similitude sobre os títulos das teses e dissertações

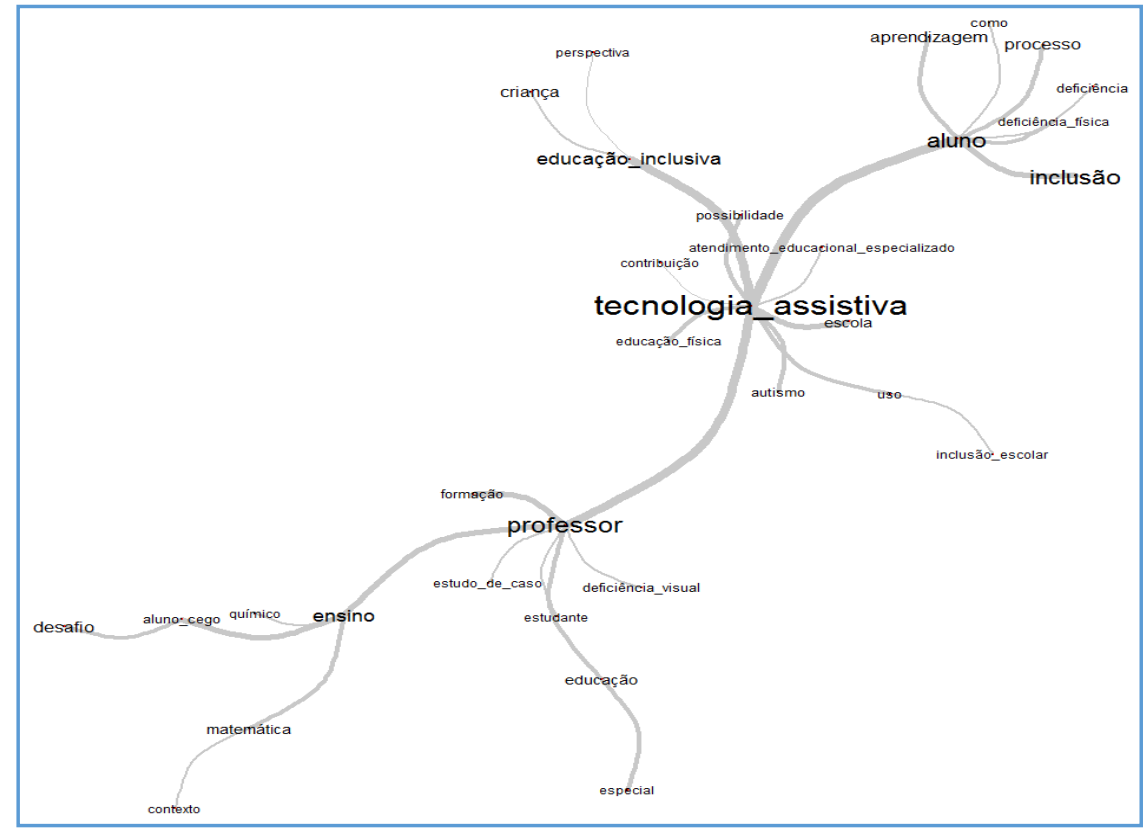

Fonte: Dados da pesquisa (2020).

Os principais temas tratados nessas teses e dissertações apresentam, pela teoria dos grafos, uma ocorrência entre as palavras e as indicações da conexidade entre elas, por meio da estrutura de organização dos títulos dos trabalhos. Nestas conexões, observou-se uma árvore de similitude em que uma das expressões se apresenta como norte para toda a árvore, que é a "Tecnologia Assistiva", ela vai produzindo sentido explicativo para os eixos "educação inclusiva”, "professor”, “aluno”, “inclusão”, “ensino”, "processo”, "aprendizagem” (Ver figura 1). Importante observar que quando se relaciona com as demais produções destes pesquisadores, percebe-se que a Educação Especial vem sendo discutida de forma que:

Busca as respostas em suas práticas e nas teorias que a nutrem, tem avançado em seu campo de estudo sistematizando o conhecimento, analisando, definindo, compreendendo este objeto e construindo sua própria dimensão semântica ou substantiva, avançando, portanto, para ser muito mais que uma modalidade e aproximando-se a passos firmes de ser considerada uma disciplina (DONOSO, 2017, p. 89)

Refletindo esse processo de sistematização na produção do conhecimento, vale dizer que uma parte significativa do campo de estudo destas teses e dissertações foi feita com professores da EEI (33,3\%), como também foram produzidas com alunos na Educação Básica com alguma deficiência $(35,7 \%)$, alunos do Ensino Superior $(2,4 \%)$ e pelos grupos dos professores e alunos (23,8\%), e dos professores, alunos, pais e gestores (4,8\%). Além disso, pela natureza dos sujeitos da pesquisa, observou-se que a maioria das teses e 
http://dx.doi.org/10.5902/1984686X64421

dissertações se apresentam pela abordagem qualitativa (81\%) ou quali-quantitativa (19\%) (Ver tabela 2). Nessa perspectiva, a pesquisa de Santos, Kautsky \& Calixto (2019) sobre Educação especial nos programas de mestrado e doutorado em educação da Universidade Federal do Espírito Santo observam que

Há destaque para a perspectiva qualitativa, utilizando como instrumentos: narrativas, história de vida e estudo de caso. Sendo o propósito das pesquisas, nestas abordagens o de compreender a partir de uma perspectiva sóciohistórica, o participante da pesquisa e a si mesmo. (SANTOS; KAUTSKY; CALIXTO, 2019, p. 13)

Ao considerar as escolhas metodológicas tanto dos trabalhos pesquisados neste artigo quanto no observado por Santos, Kautsky \& Calixto (2019), registra-se uma abordagem mais qualitativa que não produz um padrão de procedimento para a coleta de dados (ver figura 2), mas que os procedimentos fazem um certo diálogo com a metodologia escolhida pelos autores.

Tabela 2 - Perfil dos pesquisados nas Teses e dissertações

\begin{tabular}{l|l}
\hline VARIÁVEIS & $\mathbf{n}(\%)$ \\
\hline Perfil dos pesquisados & \\
Professores da educação inclusiva & $14(33,3)$ \\
Alunos deficientes da educação básica & $15(35,7)$ \\
Professores e alunos & $10(23,8)$ \\
Alunos do ensino superior & $1(2,4)$ \\
Professores, alunos, pais e gestores & $2(4,8)$ \\
Total & $42(100)$ \\
\hline Abordagem da pesquisa & \\
Qualitativa & $34(81)$ \\
Quanti-qualitativa & $8(19)$ \\
Total & $42(100)$ \\
\hline TOTAL & $42(100)$ \\
\hline
\end{tabular}

Fonte: Dados da pesquisa (2020).

Na verdade, ao verificar a relação da abordagem metodológica com os instrumentos de construção das informações destas teses e dissertações pela teoria dos grafos, fazendo uma ocorrência entre as palavras e as indicações da conexidade entre elas, por meio da estrutura de organização dos instrumentos de pesquisa, sobressaíram as seguintes estruturas: estudo de caso, entrevista, observação, questionário, grupo focal, análise de conteúdo, aluno, professor, formação, ensino, escola. As pesquisas em estudo trazem como questões primeiras verificarem as relações das TA com a EEI, com os principais atores que são os professores e alunos, permeados pelos desafios para o ensino e aprendizagem. Ainda é possível perceber que nessa estrutura de ligação de palavras, o termo TA ganha evidência no nó de conexidade entre as palavras. (Ver figura 2) 
http://dx.doi.org/10.5902/1984686X64421

Figura 2 - Árvore de similitude dos instrumentos de pesquisa das teses e dissertações

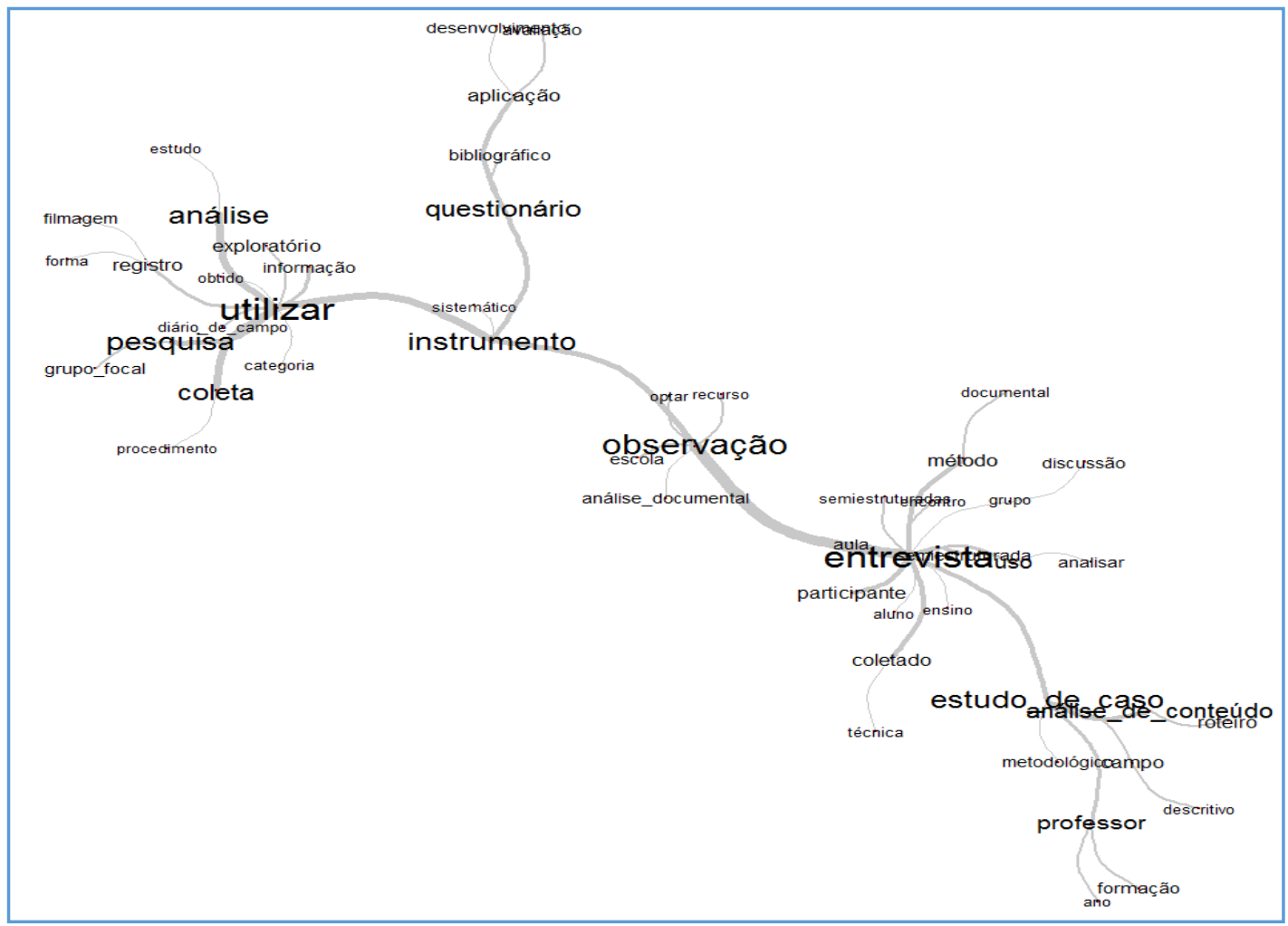

Fonte: Dados da pesquisa (2020).

Ao revelar a preponderância da abordagem qualitativa pelo diálogo dos instrumentos de coleta de informações, os estudos mostram o cuidado em escutar para interpretar o universo da EEI pelos professores, alunos, pais, ambiente escolar e os recursos da TA. Silva (2019) relata na metodologia de sua tese que como "instrumentos de coleta de dados, realizou entrevista com os profissionais da escola e pais, além da observação da sala de aula e sessões de intervenção com uso de recursos de CAA". Nesse sentido, Assante (2016), em sua dissertação, utilizou o grupo focal e aplicação de um questionário sobre o robô, para assim mensurar dados que tornasse a sua pesquisa relevante. Conforme Gatti (2010)

[...] Na pesquisa, muito importante são os dados com que trabalhamos. E dado pode ser desde o conjunto de medidas bem precisas que tomamos até depoimentos, entrevistas, diálogos, discussões, observações, etc. de que servimos de geração para a geração de algum conhecimento que acrescenta alguma coisa à compreensão do problema que nos interessa. (GATTI, 2010, p.10-11).

É possível perceber que os diversos procedimentos metodológicos se relacionam com os objetivos das pesquisas principalmente porque introduzem nas investigações as intersecções entre Tecnologia Assistiva e Educação Especial Inclusiva. O que mostra a 
Tecnologia Assistiva como recurso/ estratégia metodológica da Educação Especial Inclusiva, no sentido de promover um conhecimento autônomo, para independência e inclusão social. Esse conceito de TA pode ser representado por meio da figura 3 que contém uma nuvem de palavras mais representativas, são elas: "deficiência", "recurso", "promover", "autonomia", "serviço", "conhecimento", "independência", "inclusão social".

Figura 3 - Nuvem de palavras sobre o conceito de Tecnologia Assistiva

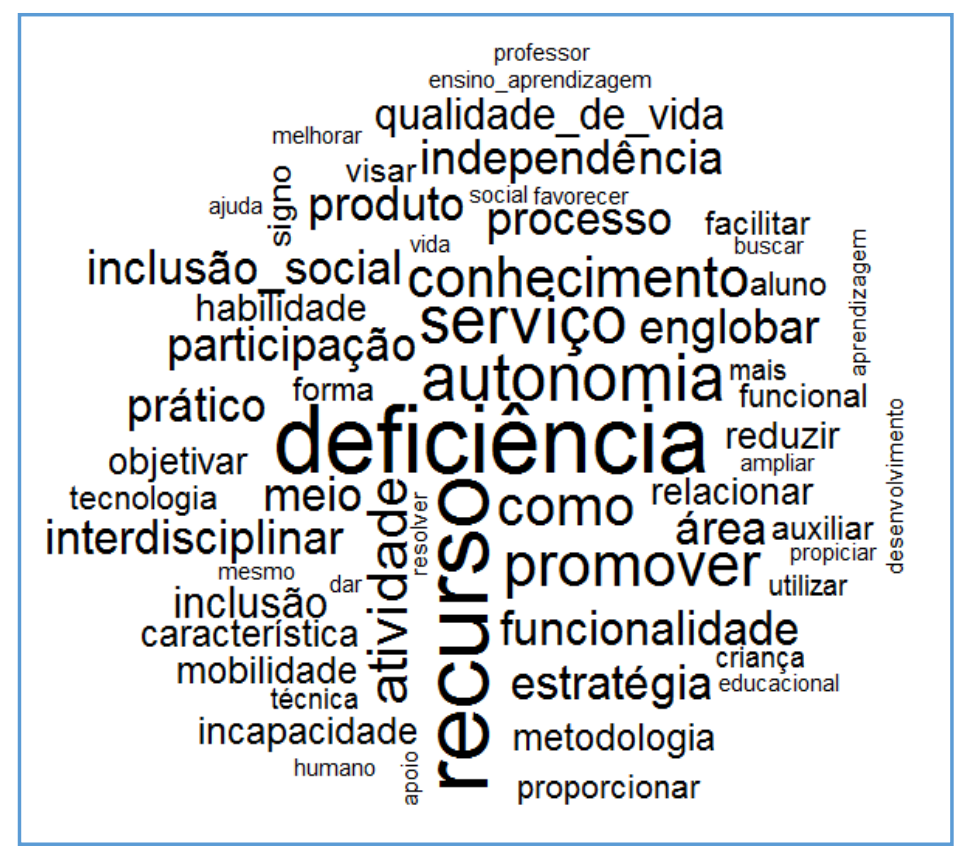

Fonte: Dados da pesquisa (2020).

Estudos como os de Alves (2017), entende que a TA "tem um potencial inclusivo por propiciar meios para que a pessoa com deficiência desenvolva suas habilidades, atividades diárias e se insira no meio social e se constitua como cidadão de direitos". Nessa linha, Silva (2019) percebe a TA como "um importante meio de potencializar o desenvolvimento da pessoa com deficiência, fortalecendo a autonomia e autoestima, o que retira o foco da deficiência da pessoa e valoriza suas habilidades e potencialidade de vida e inclusão social". Sob essa perspectiva, Biazus \& Rieder (2019), ao fazer uma revisão sistemática sobre uso da Tecnologia Assistiva na Educação Inclusiva no Ambiente Escolar, verifica que a TA pode:

[...] fornecer intervenções para produzir mudanças ambientais que contribuam para a melhoria da qualidade de vida; qualificação dos professores como um preditor na qualidade do processo na El; falta de serviços especializados para estudantes com NEEs; características do aluno e do professor combinados podem influenciar o nível de uso de TA; EI depende de diversas abordados tais como questões acadêmicas, comportamental, mobilidade / acessibilidade, social e meio de transporte; maior compreensão sobre aplicação da TA na El e novas pesquisas devem ser direcionadas a essa área. (p.10) 
Pode-se verificar que, de uma maneira e nas Teses e dissertações, pode existir uma forte aliança conceitual entre a TA e a EEI. Para se ter uma ideia, observa-se por meio da teoria dos grafos uma ocorrência entre as palavras e as indicações de conexidade entre elas, por meio da estrutura de organização do conceito de Educação Especial Inclusiva já lançada pela TA, principalmente nas seguintes palavras/ expressões: aluno, necessidade, deficiência, ensino, processo, aprendizagem, direito, assegurar, acesso, participar, inclusão, igualdade (Ver figura 4).

Figura 4 - Árvore de similitude sobre o conceito de El das teses e dissertações

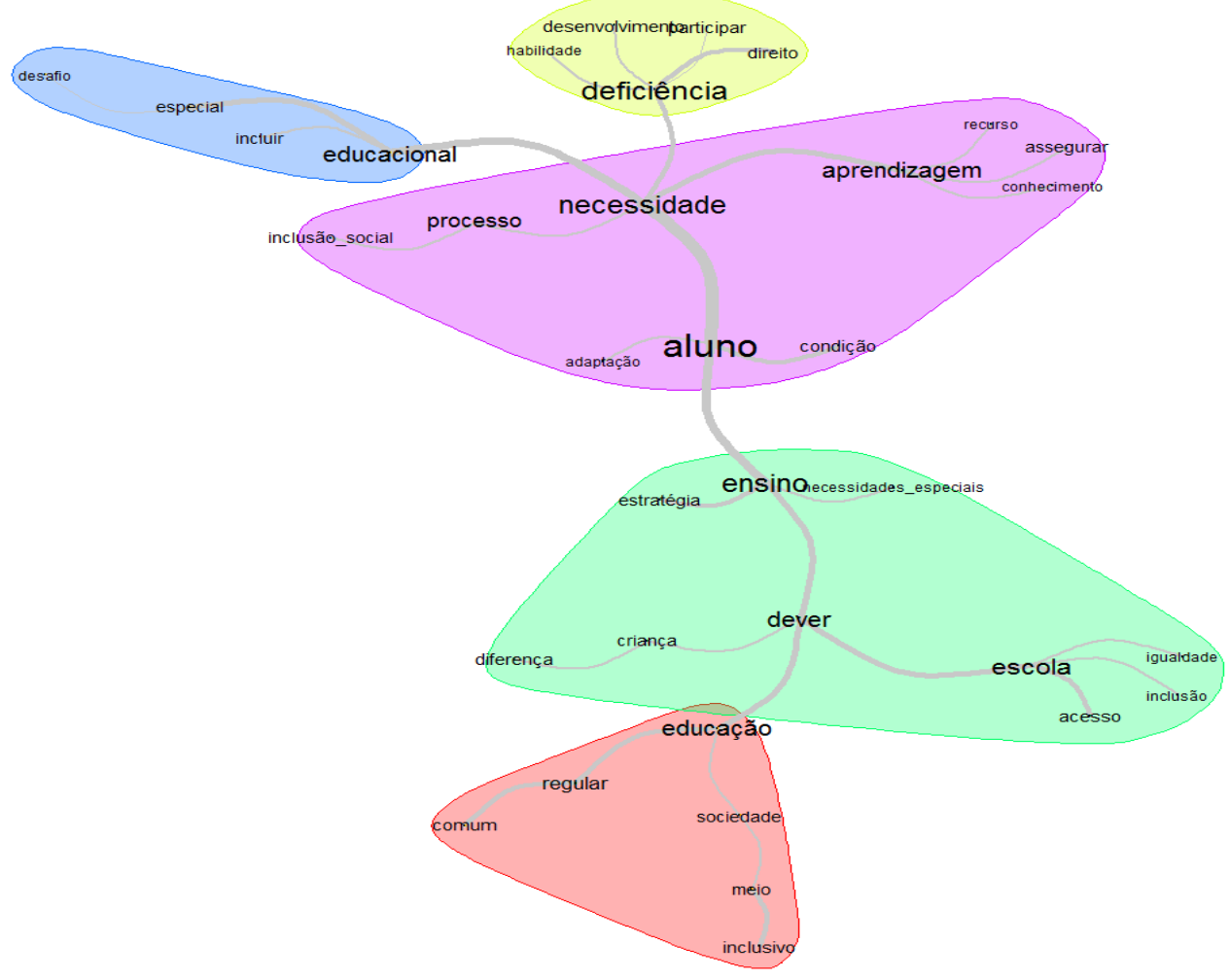

Fonte: Dados da pesquisa (2020).

Essas palavras da figura 4, com indicações de conexidade, ganham dimensões interpretativas de uma EEI com acesso e permanência à uma educação participativa, de autonomia do saber. Nos trabalhos como de Ramos (2015), entende-se que a EEI consiste em um dos grandes desafios da contemporaneidade, de criar possibilidades significativas para as práticas pedagógicas, com a participação efetiva dessas pessoas, condição sine qua non para a efetividade de uma pedagogia critica em instituições escolares emancipatórias. Por essa perspectiva, Nascimento (2019) observa que a EEI tem como proposta assegurar a todos igualdade de condições de acesso e permanência na escola 
sem qualquer discriminação. No entanto, Biazus \& Rieder (2019) destacam três grandes obstáculos à essa proposta:

\begin{abstract}
a imprecisão do atual conceito de TA, as dificuldades no acesso aos recursos, e a falta de formação dos profissionais envolvidos. A direção tomada indica que há cada vez mais demandas pela manutenção dos investimentos realizados no país, como capacitação de recursos humanos e desenvolvimento de ações mais assertivas quanto ao uso mais eficiente desses recursos no contexto educacional brasileiro, no sentido de que ele realmente atinja seus objetivos na garantia de autonomia e participação nas atividades cotidianas. (p.11)
\end{abstract}

Mesmo diante desses obstáculos, observam-se nas teses e dissertações analisadas que os objetivos propositivos das interações entre alunos, professores e escolas mediados pela TA põem em evidência a "participação para a autonomia do saber". Isso foi o que mostrou a teoria dos grafos, pela ocorrência entre as palavras e as indicações da conexidade entre elas, estruturando a organização dos objetivos gerais das pesquisas em estudo, especialmente as seguintes: "aluno", "professor", "escola", "analisar", "processo", "ensino" (Ver figura 5).

Figura 5 - Árvore de similitude sobre os objetivos gerais das teses e dissertações

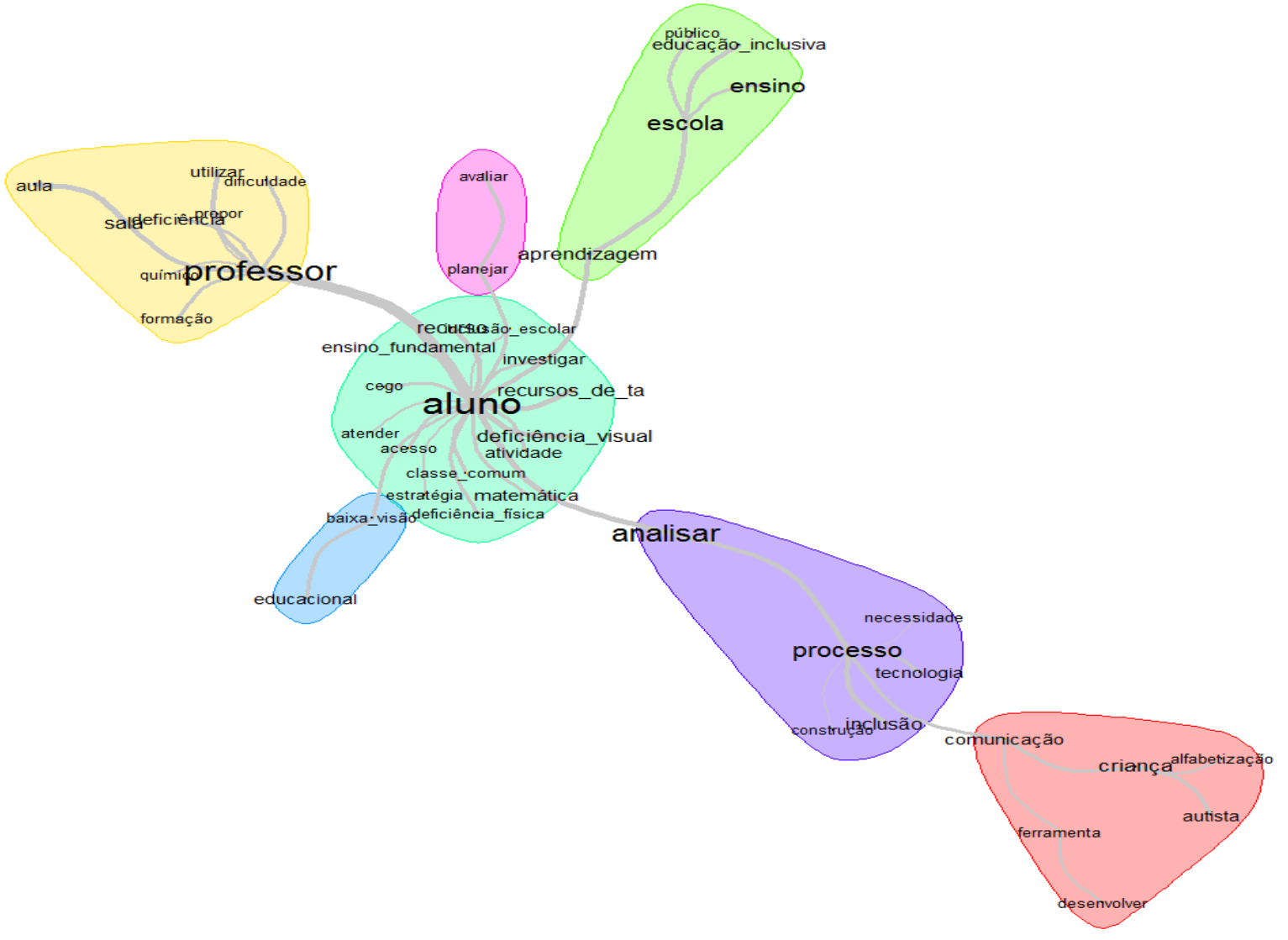

Fonte: Dados da pesquisa (2020). 
http://dx.doi.org/10.5902/1984686X64421

É importante dizer que faz parte destas teses e dissertações, além de conhecer a relação entre TA e EEI, indicar ações para transformações das propostas de educação especial inclusiva. Isso foi o caso, por exemplo, da dissertação de Vieira (2018), que objetivou refletir e analisar o uso das tecnologias da informação e comunicação no processo de inclusão de crianças com transtorno de espectro autista e apontar caminhos possíveis para o trabalho na sala de aula com essas crianças. Além dele, pode-se destacar também a pesquisa de Bruce (2015), que visou analisar na política de educação especial inclusiva a implementação de recursos de TA que possibilitem a participação e aprendizagem de alunos com deficiência física na escola. Por essa vertente, é possível apontar estes trabalhos sob o horizonte de que

\footnotetext{
O ensino colaborativo é um método amplamente utilizado para incluir e apoiar os alunos com NEEs para proporcionar a todos os alunos acesso igual à educação [... mas] há uma escassez de pesquisa sobre sua implementação e resultados, e os poucos estudos existentes estão limitados aos resultados acadêmicos e testes (BIAZUS; RIEDER, 2019, p.10)
}

Embora seja possível trazer alguns pontos de conexão destas teses e dissertações com o método colaborativo, Biazus \& Rieder (2019) lembram que os estudos estão mais limitados aos resultados acadêmicos e testes. Pensando nisso, utilizou-se da análise lexical de Classificação Hierárquica Descendente, do Iramuteq, para explorar melhor os resultados destas pesquisas. Essa análise "identifica padrões repetitivos de linguagem" e "possíveis associações do material textual, com variáveis descritivas previamente identificadas" (JUSTO; CAMARGO, 2014, p. 48). O programa dividiu o corpus em 119 segmentos de texto, identificou 1.278 formas distintas e 4.167 ocorrências; reteve 106 dos 119 segmentos, o que representa $89,08 \%$ de aproveitamento do corpus. No agrupamento por classes, os segmentos de texto compuseram sete classes, apresentadas na figura 6 .

Lendo o Dendograma, da esquerda para a direita, é possível observar que, num primeiro momento, o corpus foi dividido em dois subcorpus, resultando na classe 7 , com $13,2 \%$ de segmentos de textos aproveitados. Num segundo momento, um subcorpus foi dividido em dois, resultando na classe 6 , com 12,3\% de segmentos de textos aproveitados. Num terceiro momento, um subcorpus foi dividido em dois, resultando, de um lado, as classes 2 e 4 , que somam 29,2\% de segmentos aproveitados e do outro a classe 5, com $16 \%$ dos segmentos aproveitados. Num quarto momento, um subcorpus foi dividido em dois, resultando nas classes 1 e 3, que somam 29,2\% de segmentos aproveitados. Finalizaram-se as repetições, pois, as sete classes mostraram-se estáveis. (ver figura 6) 
As sete classes encontradas nos resultados das teses e dissertações se apresentam hierarquicamente. As classes 6 e 7 vão dando sentido explicativo às demais. Nessa última (7), aborda-se como preponderante em todos os trabalhos que discutem a relação da EEI com TA "a importância da TA no processo de ensino aprendizagem". As palavras hierarquizadas nessa classe (triangular, lápis, escrita, avaliação, produto) encontram sentido, por exemplo, na dissertação de Lugli (2018), em que os resultados demonstraram ter o uso do fantoche eletrônico promovido mais de $80 \%$ de cenas de atenção conjunta e o aumento de três casos positivos com fantoche não eletrônico para quase 10 com fantoche eletrônico, representando um ganho de mais de 200\%. Nessa linha, Assante (2016) verificou nas suas análises que havia uma diferença positiva considerável na concentração de sinais de crianças surdas e ouvintes após a intervenção da TA. (ver figura 6)

Embora a classe 7 mostre a importância da TA no processo de ensino e aprendizagem, a classe 6, intitulada como "pouco contato dos professores com a TA", aponta suas dificuldades com as seguintes palavras: "aluno", "recurso", "falta" e "necessidade". Isso porque, segundo Gomes (2015), os professores receberam orientações quanto ao uso da TA, porém não participaram do processo de implantação e escolha. Por esse caminho, Basegio (2016) verificou que os participantes (professores) mencionaram a necessidade de uma orientação, formação e tempo para utilização da TA no ensino e aprendizagem. (ver figura 6)

Na classe 5, categorizada como "as estratégias de ensino e aprendizagem mediadas pela TA", observam-se as palavras "atendimento", "aprendizagem”, "inclusão", "favorecer", "ensino", como horizontes interpretativos. Especificamente, Pauli (2019) nota que estratégias de ensino são cruciais para fomentar as aprendizagens de conceitos estatísticos para alunos com deficiência visual. E Simões (2018) aponta as estratégias do acolhimento e do atendimento educacional especializado com vistas a efetiva aprendizagem do aluno com deficiência visual. (ver figura 6)

No terceiro nível, as classes 4 e 2 são importantes juntas porque se definem como desdobramentos das categorias anteriores, intitulando-se de "recursos didáticos de ensino e aprendizagem mediados pela TA". Para especificar esse entendimento, observa-se nas seguintes palavras pontos chave: deficiência, perspectiva, manipulável, criança, auxiliar, interação. Além disso, outros exemplos trazem resultados com esses recursos, como: a de que a matemática quando contempla o uso de materiais concretos e manipuláveis em sala de aula torna essa disciplina mais prazerosa para o aluno, inclusive para aquele que 
apresenta alguma deficiência (AQUINO, 2018); e a de que foram observados dois hardwares, um de TA fabricado no Brasil e outro compatível com ele, o primeiro facilita a digitação de pessoas com movimentos limitados em seus membros superiores e que, se utilizados em conjunto, podem auxiliar o uso do computador por meio do piscar de olhos (PAMPLONA, 2016). (ver figura 6)

Figura 6 - Dendograma - Classificação Hierárquica Descendente sobre os resultados das teses e dissertações

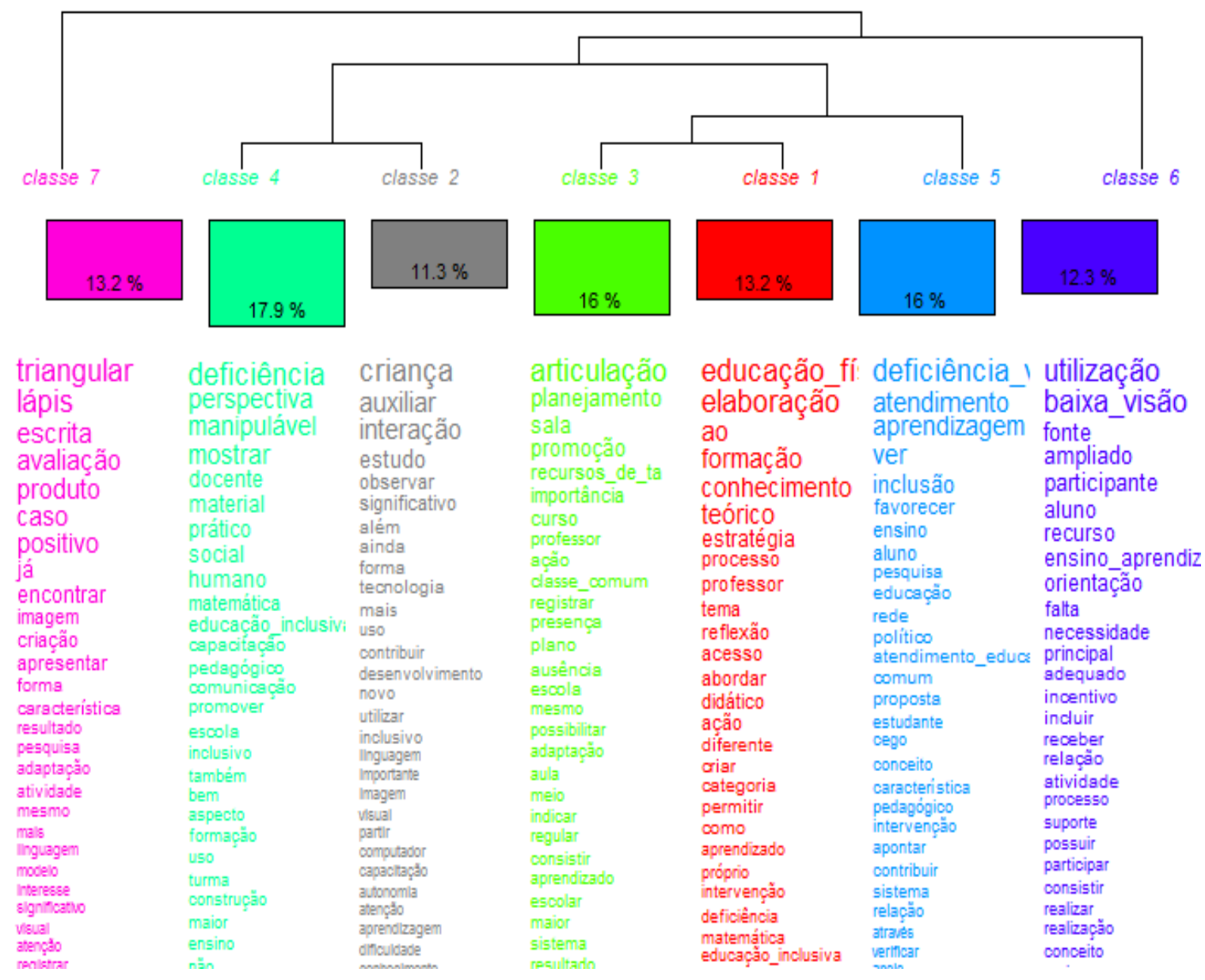

Fonte: Dados da pesquisa (2020).

As classes 1 e 3 abordam a questão da "necessidade da Formação de Professores mediada pela TA para atuar na Educação Especial Inclusiva". No trabalho de Toloi (2015), por exemplo, salienta que as aulas de formação propiciaram aos professores conhecimentos teóricos e práticos relacionados à Educação Física e o uso de estratégias e recursos de TA. Na verdade, segundo Miranda (2016), a formação inicial e continuada tem influência direta nesse processo, principalmente porque permite ao professor mediar 0 ensino e aprendizagem adaptados. Além disso, Candido (2018) aponta que a formação de 
http://dx.doi.org/10.5902/1984686X64421

professores deve estar relacionada à disponibilidade de materiais didáticos acessíveis, bem como o interesse, a intenção, o desejo de fazer diferente do professor, tornando-os imprescindíveis para o processo de inclusão escolar. (ver figura 6)

Deste modo, as classes produzidas pela CHD da figura 6 ganharam sentido ao relacionarem EEI e TA, evidenciando questões em torno da educação especial inclusiva no processo de ensino-aprendizagem dos alunos com alguma deficiência. As inquietações sobre a maneira como os recursos de Tecnologia Assistiva podem auxiliar o processo de aprendizagem mostrou que há um envolvimento dos alunos nas atividades, embora à participação ativa em seu processo de aprendizagem dependesse de formação docente para atuar com esses recursos, produzindo um dos maiores desafios.

\section{Considerações finais}

Este estudo sobre as teses e dissertações produzidas nas Pós-Graduações do Brasil, analisadas no período de 2015 a 2019, teve a intenção de verificar em que medida a produção cientifica sobre EEl, em nível de mestrado e doutorado, traz elementos importantes para situar a relação com as TA. Como forma de encadear a discussão, trouxe como pano de fundo a relação das trajetórias dos autores pesquisados com os processos constitutivos desse tipo de produção do conhecimento.

Pode-se perceber que as trajetórias dos autores estavam diretamente relacionadas com a temática da educação especial, embora nem todas estivessem intimamente ligadas as TA. Vale salientar que pelo menos as teses ou dissertações destes autores dialogavam de forma intrínseca com a TA. Nessa relação, observou-se a discussão teórica para definir o que compreendiam por El e TA, bem como o papel desta última na atualidade e atualização de recursos didático-pedagógicos para a formação inicial e continuada de professores que atuam na Educação Especial Inclusiva.

Nesse âmbito, evidenciou-se, assim como em outros estudos do tipo "estado da arte", revisão sistemática ou integrativa, uma forte necessidade de trazer para frente da discussão não somente a atuação das instituições de ensino para utilização de recursos com TA, mas também que sejam propositores de TA junto aos educandos, produzindo assim um processo de ensino-aprendizagem para autonomia dos sujeitos sociais, independente de alguma deficiência.

Este estudo abre portas para novas pesquisas porque evidencia um número significativo de trabalhos sobre El e TA nas Pós-Graduações do Brasil nos últimos anos de 
forma interdisciplinar. Essas relações entre EI e TA não foram mostradas somente pela importância desse diálogo, mas como processos que estão sendo construídos nos espaços educativos recheados por limitações, necessidades e experiências que se mostram significativas para discutir o ensino e aprendizagem pela Educação Especial Inclusiva. Portanto, novas pesquisas do tipo "Estado da Arte" são urgentes para ampliar e ressignificar essas produções do conhecimento.

\section{Referências}

ALVES, David de Abreu. Tecnologia Assistiva e inclusão: a construção da consciência espacial cidadã de deficientes visuais. Orientador: Antônio Carlos Pinheiro. 243 f. Dissertação (Mestrado em Geografia), Universidade Federal do Paraíba, João Pessoa, 2017.

AQUINO, Adelyn Barbosa de. Contribuições do uso da comunicação alternativa para crianças com deficiência intelectual na Educação Infantil. Orientador: Tícia Cassiany Ferro Cavalcante. 114 f. Dissertação (Mestrado Em Educação), Universidade Federal de Pernambuco, Recife, 2018.

ASSANTE, Lidiane de Souza. A inclusão do robô humanóide não como recurso tecnológico no processo do ensino aprendizado da Língua Portuguesa na Educação Especial. Orientador: Marlene Araújo de Faria. 140 f. Dissertação (Mestrado em Engenharia de Produção), Universidade Federal do Amazonas, Manaus, 2016.

BARDIN, Laurence. Análise de conteúdo. 1. ed. Lisboa: Edições 70, 1977.

BASEGIO, Antonio Carlos. Percursos da Tecnologia Assistiva no contexto de educação inclusiva e a luta por reconhecimento das diferenças. Orientador: Elaine Conte. 175 f. Dissertação (Mestrado em Educação), Centro Universitário La Salle, Canoas, 2016.

BIAZUS, Graziela Ferreira; RIEDER, Carlos Alberto Mello. Uso da tecnologia assistiva na educação inclusiva no processo de alfabetização de escolares: revisão sistemática. Revista Educação Especial, 32, e69/ 1 -15, 2019. Disponível em: https://doi.org/10.5902/1984686X33317. Acesso em: 3 set. 2019.

BRASIL. Decreto no 5.296 de 02 de dezembro 2004. Brasília, 2004.

BRASIL. Ministério da Educação. Política Nacional de Educação Especial na Perspectiva da Educação Inclusiva. 2008.

BRUCE, Christiane da Costa. A política de educação inclusiva: a tecnologia assistiva como possibilidade de participação e aprendizagem de alunos com deficiência física na escola. Orientador: Maria Almerinda de Souza Matos. 88 f. Dissertação (Mestrado em Educação), Universidade Federal do Amazonas, Manaus, 2015. 
http://dx.doi.org/10.5902/1984686X64421

BUENO, José Geraldo Silveira. A educação especial nas universidades. Brasília: MEC, Secretaria de Educação Especial, 2002.

CAMARGO, Brigido Vizeu; JUSTO, Ana Maria. IRAMUTEQ: um software gratuito para análise de dados textuais. Temas Psicol. Vol. 21, n.2, p.513-8, 2014.

CANDIDO, Vilma Mussilene de Araújo. O "LIA": uma tecnologia assistiva no processo de construção de narrativas para alunos com autismo. Orientador: Filomena Maria Gonçalves da Silva Cordeiro Moita. 128f. Dissertação (Mestrado Profissional em Formação de Professores), Universidade Estadual da Paraíba, Campina Grande, 2018.

DONOSO, Elizabeth; MATURANA, Cristina Júlio; CONOJEROS, Leonor; MANGHI, Dominique; VEGA, Vavessa. ¿Es la Educación Especial una disciplina? reflexiones sobre su Objeto y Método de Estudio p.75-94. En GARRIDO, José; VEGA, Vanessa; BUSTOS, Andrea. De los fundamentos a las prácticas: algunos desafíos en la formación inicial docente. Ediciones Universitarias de Valparaíso: Valparaíso, 2017.

ECHALAR, Adda Daniela Lima Figueiredo et al. Trabalho docente mediado por tecnologias: ecos e repercussões. Educação em foco (JUIZ DE FORA), v. 23, p. 319-339, 2018.

FAZENDA, Ivani Catarina Arantes (Org.). Práticas interdisciplinares na escola. São Paulo: Cortez, 1999.

FERREIRA, Júlio Romero. Pesquisa no contexto da política em Educação Especial. In: Seminário Brasileiro de Pesquisa em Educação Especial, 2, 1991, Rio de Janeiro. Anais... Rio de Janeiro: UERJ, 1991. v. 1. p. 8-11.

GALVÃO FILHO, Teófilo Alves. Tecnologia Assistiva para uma Escola Inclusiva: apropriação, demandas e perspectivas. Orientador: Theresinha Guimarães Miranda. 346f. Tese (Doutorado em Educação) - Faculdade de Educação, Universidade Federal da Bahia, Salvador, 2009.

GATTI, Bernardete Angelina. A construção da pesquisa em educação no Brasil. Brasília: Liber Livro, 2010.

GOMES, Elayne Crystyna Pereira Borges. Tecnologia Assistiva para alunos com baixa visão nas escolas estaduais de São Luís: utilização na classe comum e na sala de recurso multifuncional. Orientador: Silvana Maria Moura da Silva. 160 f. Dissertação (Mestrado em Educação), Universidade Federal do Maranhão, São Luís, 2015.

\section{LUGLI, Luciano Cassio. Prototipagem de soluções tecnológicas, alfabetização} matemática na Educação Infantil e deficiência sensorial, Parametrização de características assistivas. Orientador: Deise Aparecida Peralta. 130 f. Dissertação (Mestrado em Ensino e Processos Formativos, Universidade Estadual Paulista "Júlio de Mesquita Filho, Rio Claro, 2018.

MENDES, Felismina Rosa Parreira; ZANGÃO, Maria Otília Brites; GEMITO, Maria Laurência Grou Parreirinha; SERRA, Isaura da Conceição Cascalho. Social Representations of nursing students about hospital assistance and primary health care. Rev Bras Enferm [Internet]. 69(2):321-8, 2016. Disponível em: http://dx.doi.org/10.1590/0034-7167.2016690218i. Acesso em: 3 set. 2019. 
MANZINI, E. J. Formação do professor para o uso de tecnologia assistiva.In: Cadernos de Pesquisa em Educação. PPGE/UFES, Vitória, ES. a. 9, v. 18, n. 36, p. 11-32, jul./dez. 2013.

MIRANDA, Edinéia Terezinha de Jesus. $O$ aluno cego no contexto da inclusão escolar: desafios no processo de ensino e de aprendizagem de matemática. Orientador: Ivete Maria Baraldi, 167f. Dissertação (Mestrado em Educação para a Ciência), Universidade Estadual Paulista, Bauru, 2016.

NASCIMENTO, Edivaldo Jerônimo Pereira do. Contribuições da audiodescrição para o ensino de células animais no ensino médio. Orientador: Ernani Nunes Ribeiro. $75 \mathrm{f}$. Dissertação (Mestrado em Ensino de Biologia), Universidade Federal de Pernambuco, Vitória de Santo Antão, 2019.

NUNES, Leila Regina d'Oliveira de Paula et al. A produção discente da Pós-graduação em Educação e Psicologia sobre o indivíduo com necessidades educacionais especiais. In: MENDES, Enicéia Gonçalves et al. (Orgs.) Temas em Educação Especial: avanços recentes. São Carlos: EDUFSCar, 2004.

\section{PAULI, Patrícia Aparecida Coimbra de. A integração das tecnologias ao currículo} inclusivo de crianças com TEA: um estudo de caso. Orientador: Maria da Graça Moreira da Silva. 203 f. Dissertação (Mestrado em Educação: Currículo), Pontifícia Universidade Católica de São Paulo, São Paulo, 2019.

PAMPLONA, Thaís Christovam. Contribuições da Tecnologia Assistiva na aprendizagem online, de alunos da educação superior com deficiência física nos membros superiores. Orientador: Luciano Frontino de Medeiros. 136 f. Dissertação (Mestrado Profissional em Educação e Novas Tecnologias), Centro Universitário Internacional, Curitiba, 2016.

PELOSI, Miryam Bonadiu.; NUNES, Leila Regina d'Oliveira de Paula. Caracterização dos professores itinerantes, suas ações na área de tecnologia assistiva e seu papel como agente de inclusão escolar. Rev. bras. educ. espec., vol.15, p. 141-154, 2009.

RAMOS, Ingrid de Souza Cayres. O uso da Tecnologia Assistiva na Educação Física escolar, em uma perspectiva lúdica: desafios e possibilidades. Orientador: Cristina Maria D'Ávila. 151 f. Dissertação (Mestrado em Educação), Universidade Federal da Bahia, Salvador, 2015.

SANTOS, Laís Carla Simeão da Silva; KAUTSKY, Giselle Lemos Schmidel; CALIXTO, Rafaella Mayanne Antunes. Análise das pesquisas em Educação Especial produzidas nos cursos de mestrado em educação e doutorado em educação da UFES anos de 2013 e 2014. Anais... IV Seminário Nacional de Educação Especial; XV Seminário Capixaba de Educação Inclusiva; I Seminário de Pesquisas de Pós-Graduação Lato Sensu na Perspectiva da Inclusão [recurso eletrônico] / organização e realização, UFES, Centro de Educação. - Dados eletrônicos. - Vitória, ES: GM Gráfica Ed., 2019. 
SILVA, Lessandra Marcelly Sousa da. Do improviso às possibilidades de ensino: estudo de caso de uma professora de matemática no contexto da inclusão de estudantes cegos. Orientador: Miriam Godoy Penteado. 194 f. Tese, Doutorado em Educação Matemática, Universidade Estadual Paulista "Júlio de Mesquita Filho, Rio Claro, 2015.

SIMÕES, Guilherme Soares. Me ajuda a entender: website como ferramenta de apoio para professores no ensino de Química a estudantes com Deficiência visual. Orientador: Nilma Soares da Silva. 142 f. Dissertação (Mestrado Profissional Em Educação e Docência), Universidade Federal de Minas Gerais, Belo Horizonte, 2018.

SOARES, Magda Becker; MACIEL, Francisca. Alfabetização. Brasília: MEC/INEP/Comped, 2000.

SOUZA, Christianne Thatiana Ramos de; MENDES, Eniceia Gonçalves. Revisão Sistemática das Pesquisas Colaborativas em Educação Especial na Perspectiva da Inclusão Escolar no Brasil. Rev. bras. educ. espec., Marília , v. 23, n. 2, p. 279-292, June 2017.

TOLOI, Gabriela Gallucci. Formação de professores de educação física para inclusão educacional usando tecnologia assistiva. Orientador: Eduardo José Manzini. 212 f. Tese (doutorado em Educação), Universidade Estadual Paulista Júlio de Mesquita Filho, Marília, 2015.

UNESCO. Declaração de Incheon: educação 2030, rumo a uma educação de qualidade inclusiva e equitativa e à educação ao longo da vida para todos. In: FÓRUM MUNDIAL DE EDUCAÇÃO, 2015, Incheon. Relatório... Genebra, 2015.

VARELA, Renata Cristina Bertolozzi; OLIVER, Fátima Corrêa. A utilização de Tecnologia Assistiva na vida cotidiana de crianças com deficiência. Ciênc. saúde coletiva, Rio de Janeiro , v. 18, n. 6, p. 1773-1784, June 2013.

VIEIRA, Paulo Sérgio José. Políticas e práticas de educação inclusiva para pessoas com Deficiência visual: o caso da Escola de Música de Brasília. Orientador: Ivar César Oliveira de Vasconcelos. 154 f. Dissertação (Mestrado em Educação), Universidade Católica de Brasília, Brasília, 2018.

\section{Notas}

${ }^{1}$ Salienta-se que essa (não)relação pode ser observada por conta dos obstáculos identificados nos conceitos e práticas da TA na educação (BIAZUS; RIEDER, 2019).

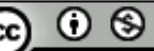
International (CC BY-NC 4.0) 